\title{
Tuberculosis in a southern Brazilian prison
}

\author{
Daniele Kuhleis $^{1,2}$, Andrezza Wolowski Ribeiro ${ }^{1,3}$, Elis Regina Dalla Costa ${ }^{3}$, \\ Patrícia Izquierdo Cafrune ${ }^{1}$, Karen Barros Schmid ${ }^{1,3}$, Lucas Laux da Costa ${ }^{1,3}$, \\ Marta Osório Ribeiro ${ }^{3}$, Arnaldo Zaha ${ }^{1}$, Maria Lucia Rosa Rossetti ${ }^{3,4} /+$
}

\footnotetext{
1Programa de Pós-Graduação em Biologia Celular e Molecular, Centro de Biotecnologia, Universidade Federal do Rio Grande do Sul, Porto Alegre, RS, Brasil 'Penitenciária Estadual do Jacuí, Charqueadas, RS, Brasil ${ }^{3}$ Centro de Desenvolvimento Científico e Tecnológico, Fundação Estadual de Produção e Pesquisa em Saúde, Porto Alegre, RS, Brasil ${ }^{4}$ Universidade Luterana do Brasil, Canoas, RS, Brasil
}

The occurrence of tuberculosis (TB) in prisons has been described as an alarming public health problem in many countries, especially in developing nations. The objective of this study was to conduct a survey among prisoners with $T B$ respiratory symptoms in order to estimate the incidence of the disease, to analyze the drug susceptibility profile and genotype the isolates of Mycobacterium tuberculosis in the city of Charqueadas, southern of Brazil. The TB incidence was 55/1,900 inhabitants in the prison; this corresponds to an incidence of 3,789/100,000 inhabitants, with a prevalence of 72/1,900 (4,960/100,000 inhabitants). Drug susceptibility test was performed and, among the analyzed isolates, $85 \%$ were susceptible to all drugs tested and $15 \%$ were resistant to at least one drug, of which $89 \%$ were resistant only to isoniazid (INH) or in combination with another drug. The genotype classification of spoligotyping analysis showed that $40 \%$ of the isolates belong to LAM family, 22\% to T family, $17.5 \%$ to Haarlem family, $12.5 \%$ to $U$ family and $3 \%$ to $X$ family. The shared international spoligotypes most frequently found were $729(27 \%)$, 50 (9.5\%), $42(8 \%), 53(8 \%)$ and $863(8 \%)$. In conclusion, it was observed that TB in this specific population had been caused, mostly, by strains that have been transmitted in the last few years, as demonstrated by the large level of genotype clustering. In addition, it was found specific large clusters, which were not often found in the general population from the same period and in the same region.

Key words: Brazilian prison - genotyping - prevalence - tuberculosis

The occurrence of tuberculosis (TB) in prisons has been described as an alarming public health problem in many countries, particularly in developing nations (Banu et al. 2010, Todrys et al. 2011). Furthermore, the TB incidence rate is higher in prisons than at the national level in Azerbaijan (61 times higher), Spain and Germany (10 times higher) and France (4 times higher) (Aerts et al. 2006). Data from Brazil are scarce; however, the TB prevalence in prisons in the city of São Paulo (SP) was 70 times higher than among the general Brazilian population (Abrahão et al. 2006). In a Rio de Janeiro (RJ) state prison, the prevalence was 35 times higher than in the state-wide general population (Legrand et al. 2008).

The prison population is predominantly young and male with a low education level and prisoners usually originate from disadvantaged communities with high TB rates (March et al. 2000). The prisoners usually live in unhealthy settings and do not have the resources or habits to keep themselves healthy. The prisoners may also have unhealthy habits or addictions that contribute to their poor health and have risk factors for developing TB, such as alcoholism, smoking and drug use. For these reasons, inmates enter prison with pre-existing illnesses

+ Corresponding author: mrossett@terra.com.br

Received 31 October 2011

Accepted 9 July 2012 or with a higher risk of becoming ill compared to the general population (Dara et al. 2009). When the inmates enter the prison system, they are exposed to several factors that contribute to TB evolution, such as incarceration, overcrowding, a higher prevalence of human immunodeficiency virus (HIV) infection and malnourishment (Lobacheva et al. 2007, Banu et al. 2010, Abebe et al. 2011, Todrys et al. 2011).

A biomolecular approach used in several countries has proven that TB transmission inside prisons contributes significantly to the high TB incidence rates observed in prison populations (Clark et al. 1997, Ijaz et al. 2004). Methods such as spoligotyping are less discriminatory than other genotypic analysis systems such as minimum inhibitory concentration-variable-number tandem-repeat; however, spoligotyping can be useful when patterns from TB cases are compared with the international bank (SpolDB4) of Mycobacterium tuberculosis (Mtb) isolates or the data from other countries or communities. This approach has shown that some emerging Mtb strains induce more severe forms of TB or manifest higher failure or relapse rates than other strains (Zhang et al. 2005, Brudey et al. 2006, Lazzarini et al. 2008). Additionally, this approach has helped to explain the spread of Mtb worldwide and revealed the predominance of different geographical genotypes (Brudey et al. 2006, Filliol et al. 2006, Gagneux et al. 2006). Moreover, a quick identification of mycobacteria within the Mtb complex (MTC) is enabled by this approach and the transmission and evolution of these microorganisms can be examined (Supply et al. 2001, Ignatova et al. 2006). In Spain, one institution characterised 
the transmission as recent and determined that it was acquired within the institution in two-thirds of the identified cases (Clark et al. 1997).

In addition, difficulty in accessing health care and poor adherence to treatment plans contribute to delayed diagnosis, disease transmission and the emergence of multidrug-resistant TB (MDR-TB) strains (Aziz et al. 2006), which are particularly common in prisons (Banu et al. 2010).

Prison overcrowding and the circulation of visitors and workers in prisons, between prisons and within the general population can lead to the swift transmission of TB, including drug-resistant forms, both inside and outside of the prison setting. Released prisoners can infect people in their communities; this transmission represents a serious health public risk (Mac Neil et al. 2005, Todrys et al. 2011). The prison population has increased considerably in Brazil over the years, making prisons the perfect places for TB transmission (Baptista et al. 2002). These circumstances reveal that urgent actions must be taken to detect and treat TB in inmates and trace the TB transmission routes in the community and in prisons (Abebe et al. 2011).

In this study, a survey was conducted among prisoners with TB respiratory symptoms in the metropolitan region of the city of Porto Alegre, the capital of the state of Rio Grande do Sul (RS), South Region of Brazil. The objectives of this work were to estimate the prevalence of the disease, to analyse the drug susceptibility profile of the prison population and to genotype the isolates of $\mathrm{Mtb}$ to better understand disease transmission among prison.

\section{PATIENTS, MATERIALS AND METHODS}

Setting - RS is the most southern Brazilian state and its capital, Porto Alegre, has 1.4 million inhabitants (Brazilian Institute of Geography and Statistics) (ibge.gov.br/ cidadesat/topwindow.htm?1). RS has a TB incidence of 47 per 100,000 inhabitants [State Centre for Health Surveillance of RS (CEVS/RS) (saude.rs.gov.br/wsa/portal/ index.jsp?menu $=$ organograma\&cod $=4442$ ) and Porto Alegre has an incidence of 120 per 100,000 inhabitants, which is the highest incidence rate of TB in Brazil. Approximately one third of the TB patients in Porto Alegre are co-infected with HIV, which is considerably higher than the average rate of $8-10 \%$ nationally.

Patients - This is a descriptive epidemiological study and the study population included inmates of the State Penitentiary of Jacuí (PEJ), Charqueadas, RS, which receives prisoners from Porto Alegre and its metropolitan region.

From August 2007-August 2008, a screening questionnaire was given to 1,900 prisoners. The inclusion criteria were cough for more than three weeks, signing an informed consent form and answering the questionnaire. Two sputum samples were collected from each participant on different days and forwarded to and processed at the Centre for Scientific and Technological Development of the State Foundation of Production and Health Research (FEPPS). Each patient was included in the study only once and contributed only one isolate.
Ethics - This work has approval from the ethical committee on research of the FEPPS/RS (410528/2006-4) and was conducted within an ethical framework.

Bacteriological analysis - The samples were decontaminated and cultured in accordance with Kudoh and Kudoh (1974). To detect Mtb, Ziehl-Neelsen smears and staining were prepared (BK). The samples were classified according to the National Laboratory Guidelines for Surveillance of Tuberculosis and other Mycobacteria (MS/SVS 2008). After identification at the species level through an analysis of the morphologic and biochemical characteristics (MS/SVS 2008), the Mtb isolates were stored in a $\mathrm{pH} 6.8$ phosphate buffer and frozen at $-20^{\circ} \mathrm{C}$.

Drug-susceptibility testing (DST) - DST was performed using the $1 \%$ proportion method on LowensteinJensen medium as standardised by Canetti et al. (1969).

DNA extraction and genotyping by spoligotyping The genomic DNA from the culture was extracted by the CTAB method (van Embden et al. 1993). The strains were spoligotyped following the Kamerbeek et al. (1997) method. The following definition was adopted: a cluster was a group of two or more patients whose genotypes had $100 \%$ identical spoligotypes.

\section{RESULTS}

Among 1,900 inmates of the PEJ, 392 (20.6\%) had TB respiratory symptoms. Of these 392 inmates, 350 (89\%) had contact with TB within the PEJ, 35 (8.9\%) had a previous contact with TB outside the institution and, after their imprisonment, they had additional TB contact. Sixty-six prisoners $(17 \%)$ had at least one episode of TB in the past and $11(2.8 \%)$ were undernourished. Seventy-two patients (3.8\%) were positive for TB. Of these 72 patients, 68 (94.4\%) were both culture and smear sputum positive. Four (5.6\%) inmates were only sputum smear positive. Twenty samples $(27.8 \%)$ were paucibacillary (fewer than 20 colonies in the culture) and one sample was smear sputum positive.

The TB prevalence was 3.8\% (72 of 1,900 inhabitants). Of the TB cases, 17 patients $(23.6 \%)$ had at least one prior TB episode and were considered retreatment cases. Thus, the incidence of new cases was $2.9 \%$ (55 of 1,900 inhabitants). This incidence corresponds to an incidence of 3,789 TB cases per 100,000 inhabitants. The mean patient age was 30.64 years (ranging from 20-60) and $98.7 \%$ of cases were younger than age 45 . The demographics for the $72 \mathrm{~TB}$ patients were as follows: 56 $(77.7 \%)$ were white, three $(4.16 \%)$ were illiterate, the average number of years of education was 5.38, $46(63.8 \%)$ had a partner, $41(56.94 \%)$ were smokers, $29(40.27 \%)$ were drug users, five $(6,9 \%)$ had HIV, 64 (89\%) had contact with TB within the PEJ, eight (11\%) had a previous contact with TB outside the institution and after imprisonment had additional TB contact, $17(23.6 \%)$ had at least one episode of TB in the past and four (5.5\%) were undernourished (body mass index $<18$ ). Among the prisoners with respiratory symptoms, there was no significant difference between those with and without TB (regarding the above analysed characteristics). 
DST was performed in 60 isolates of $\mathrm{Mtb}$, as four culture samples were negative and eight isolates were not viable for the analysis. Fifty-one $(85 \%)$ of the analysed isolates were susceptible to all of the tested drugs and nine $(15 \%)$ were resistant to at least one drug. Eight $(89 \%)$ of the resistant isolates were resistant to isoniazid (INH) either alone or in combination with another drug.

Sixty-three isolates were available for genotyping. Upon genotype classification by spoligotyping as defined by Brudey et al. (2006), 25 (40\%) isolates belonged to the LAM family, $14(22 \%)$ belonged to the T family, $11(17.5 \%)$ belonged to the Haarlem family, eight (12.5\%) belonged to the $\mathrm{U}$ family, two (3\%) belonged to the $\mathrm{X}$ family and three (5\%) had an unclassified spoligopattern (not listed in the worldwide spoligotypes bank SpolDB4). Further analyses evaluating shared international spoligotype (SIT) patterns showed 55 (87.3\%) isolates clustering with 10 different SITs; 22 isolates formed LAM lineage bunches in two different clusters. The main cluster in the study had $17(27 \%)$ isolates and belonged to SIT729 (LAM1) and a cluster of five isolates belonged to SIT42 (LAM9). The second most prevalent clustering was SIT65 [T1 (T4-CE1 ancestor?)] with seven (11\%) isolates and the third most prevalent was SIT50 (Haarlem3) with six $(9.5 \%)$ isolates. Eight (12.7\%) isolates matched the eight individual SITs reported in our study as orphans by SpolDB4 (Table). Three isolates were segregated into three SITs that were not reported by SpolDB4. Of these three isolates, two could be defined as LAM by their similarity with this family, as shown in Table.

\section{DISCUSSION}

The TB prevalence found in the studied population was higher than in the general population. Despite inherent methodological study limitations (in comparing different size populations) and despite measuring incidence and prevalence in an unstable population (Rieder et al. 2011), when the incidence rates found in this study $(3,789$ per 100,000 inhabitants) were projected and compared to the number of RS cases reported during the same period (47 per 100,000 inhabitants), the PEJ prevalence was approximately 80 times higher than in the general population in RS and 32 times higher than in the general population of Porto Alegre (CEVS/RS). Several studies of prisons in SP and RJ have shown data similar to the results of the current study (Oliveira \& Cardoso 2004, Abrahão et al. 2006, Fournet et al. 2006). The reasons for the higher TB prevalence rates observed in prisons could be explained by several factors. First, prisoners have a higher risk of becoming infected with TB than the general population, as most prisons are overcrowded and a high number of prisoners share a cell with inadequate ventilation, inadequate hygiene and inadequate nutrition; in addition, prisoners have limited access to health services and spend little time outdoors. Second, the life circumstances of most prisoners (low socioeconomic and education level, narcotic drug use, HIV infection and underfeeding) can predispose them to developing active TB once they are infected (WHO 1998, Lobacheva 2007, Dara et al. 2009, Todrys et al. 2011). In this study, five $(6,9 \%)$ of the 72 TB-positive prisoners declared themselves to be HIV positive on the questionnaire and the other 67 TB-positive prisoners were unaware of their HIV status or denied their status. This method of ascertaining HIV status may be considered a limitation of the study.

When evaluating the microscopy and culture techniques used as diagnostic criteria, $45.8 \%$ of samples were positive according to both techniques. Thirty-five patients $(48.6 \%)$ were diagnosed only by culture and 20 samples $(27.8 \%)$ had growth of less than 20 colonies (paucibacillary). These findings confirm the importance of using culture, as recommended by the Brazilian Ministry of Health, which considers it the "gold standard" for detecting and identifying Mtb.

Despite its delay in producing results (approximately 4 weeks for non-automated samples) and the expected contamination rate (3-5\%), culture has good sensitivity and specificity, which enables the identification of the etiologic agent in clinically paucibacillary specimens (Campos et al. 1996, Lee et al. 1999). According to the Handbook of National Tuberculosis Laboratory Surveillance (MS/SVS 2008), 20\% more cases of pulmonary TB are found when sputum cultures are performed compared to smear-only case definitions. Culture also allows further identification of mycobacterial isolated species, susceptibility testing to anti-TB drugs and faster DNA access for molecular techniques. Culture specificity to TB diagnosis is higher than $99 \%$ and absolute specificity is achieved when the tests are performed to identify the MTC. The application of this diagnosis technique meets the recommendations of the new Guidelines of Recommendations for Tuberculosis Control (MS/SVS 2010) for vulnerable populations, which state that sputum culture should be performed whenever TB is suspected, regardless of the smear result.

Another important finding of this study concerns the resistance of Mtb to anti-TB drugs performed in 60 of 72 $(83.33 \%)$ patients. Resistance was found in nine (15\%) cases in which four (6.6\%) had monoresistance (1 drug) and five $(8.4 \%)$ had resistance to at least two drugs. This resistance prevalence was similar to the $11.1 \%$ drug resistance prevalence found in RJ prison (Sanchez et al. 2007). In both cases, the resistance prevalence was higher than the national resistance rate, which was $8.5 \%$, according to the results of the First Survey of Resistance to Anti-Tuberculosis Drugs held in Brazil in 1996 (Braga et al. 2003). These findings emphasise that directly observed treatment should be prioritised with the offering of a culture test for all high risk patients, such as drug users, alcoholics, patients being retreated to avoid the emergence of MDR strains, the homeless and patients living in closed communities (e.g., prisons, hospices, nursing homes and psychiatric hospitals).

The spoligotyping analysis showed that the three major genotypic families (LAM, T and Harlem) comprised $84.5 \%$ of the tested isolates; however, the proportion of isolates in the LAM family was lower, although this family has been found more frequently in other studies. The family LAM, which was found in $40 \%$ of isolates, is common in Africa, Central America, Europe and South America and represents $80 \%$ of all isolates in the Brazilian SpolDB4 (Brudey et al. 2006, Lipin et al. 2007, 


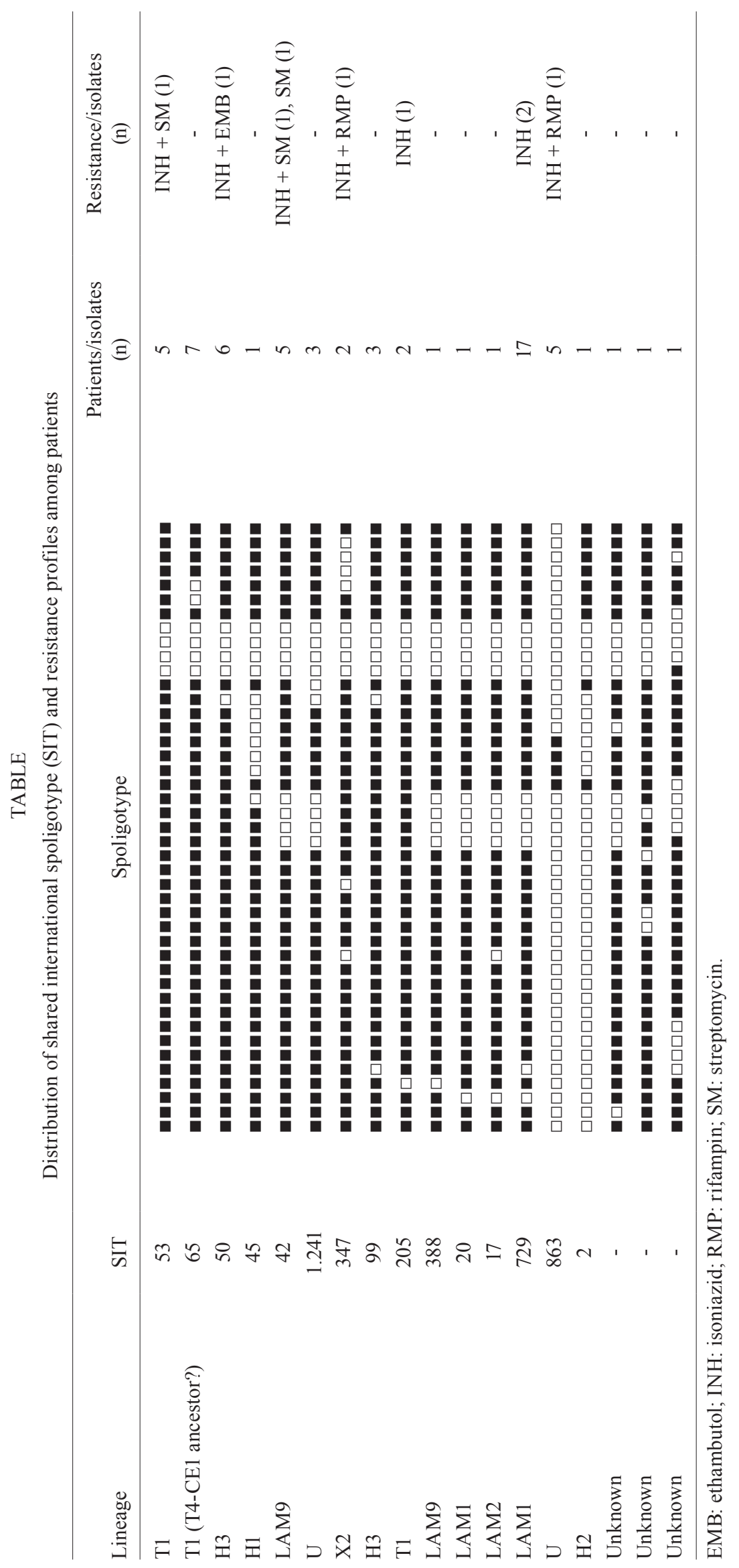


Dalla Costa et al. 2009, Ritacco et al. 2011, Perizzolo et al. 2012). The Mtb strains of the Beijing family have contributed largely to the global spread of TB (Parwati et al. 2010). However, Beijing strains were not observed in our specific population, which is in accordance with other South American studies, including Brazil (Dalla Costa et al. 2009, Ritacco et al. 2011); spoligotyping can be useful for identifying this possibility at an early stage.

LAM1 SIT729 (27\%) and U SIT863 (8\%) have been reported in other studies and have been associated with patients who have incarceration histories. Cafrune (2009) identified SIT863 in six patients who had a recent incarceration history. This spoligopattern is not often reported. One isolate was found in the United States of America, two were found in the city of Pelotas, RS and, more recently, two were found in Venezuela (Borsuk et al. 2005, Sequera et al. 2008). However, SIT729 was reported to be associated with incarceration by Cafrune (2009); $72 \%$ of the patients with this SIT were inmates. A study of MDRTB strains from RS identified three isolates belonging to the U family SIT863 and one of these isolates was in a prisoner (Perizzolo et al. 2012). The spoligotyping analysis showed that the resistant strains are probably not being spread quickly among the inmates, as the resistant genotypes differed from each other, except for two INH-resistant isolates that belonged to SIT729 (LAM1). As shown in Table, most isolates were allocated to a few clusters ( $87.3 \%$ cluster rate). This finding demonstrates that only a few strains may be responsible for the colonisation of the hosts and they prevail due to the close proximity between inmates. This process was previously reported by Moreira-Oliveira et al. (2008). This cluster rate was slightly higher than the rate usually reported for the general population (Cafrune et al. 2009, Dalla Costa et al. 2009). In addition, the clusters found in this inmate population are not often found in the general population from the same period and region (Valim et al. 2000, Cafrune et al. 2009, Dalla Costa et al. 2009, Perizzolo et al. 2012).

Further analyses indicated that the evaluated SIT patterns showed that $55(87.3 \%)$ isolates (clustered by spoligotyping) matched with 10 different SITs. Among these SITs, 22 were LAM lineage and bunched in two different clusters. The main cluster in the study had $17(27 \%)$ isolates and belonged to SIT729 (LAM1); the other cluster of five isolates belonged to SIT42 (LAM9). The second most prevalent clustering was SIT65 [T1 (T4-CE1 ancestor?)] with seven $(11 \%)$ isolates and the third most prevalent clustering was SIT50 (Haarlem3) with six (9.5\%) isolates. The Haarlem presence [11 (17.5\%)] was higher than in other studies performed only with strains from RS (Cafrune et al. 2009, Perizzolo et al. 2012). No correlation was found between the genotype families, which were defined by spoligotyping and resistance to any drug (Table).

In conclusion, it was observed that TB in this specific population had been caused primarily by strains that have been transmitted in the last several years, demonstrated by the large level of genotype clustering. In addition, specific large clusters, which were not often found in the general population, were observed. Actively searching for cases and the use of culture allowed for the early diagnosis of $25 \%$ of the expected cases in a hostile envi- ronment where health access is restricted and the health system is not always accessed. The application of DST enabled the identification of MDR bacilli and the reorientation of correct treatment for these patients. SIT729 and SIT863 may correlate with a history of incarceration; however, further studies should be conducted using other techniques of genotyping with higher discriminatory power to confirm if the isolates of each SIT are a single strain spread throughout the prison system. These findings would be important because MDR isolates with the profile SIT863 have already been found and these SITs are associated with an important vulnerable group consisting of members who are deprived of liberty.

\section{ACKNOWLEDGEMENTS}

To the research groups at CDCT/FEPPS and to PEJ staff, for their infrastructure and cooperation.

\section{REFERENCES}

Abebe DS, Bjune G, Ameni G, Biffa D, Abebe F 2011. Prevalence of pulmonary tuberculosis and associated risk factors in eastern Ethiopian prisons. Int J Tuberc Lung Dis 15: 668-673.

Abrahão RM, Nogueira PA, Malucelli MI 2006. Tuberculosis in county jail prisoners in the western sector of the city of São Pau1o, Brazil. Int J Tuberc Lung Dis 10: 203-208.

Aerts A, Hauer B, Wanlin M, Veen J 2006. Tuberculosis and tuberculosis control in Europeans prisons. Int J Tuberc Lung Dis 10: 1215-1223.

Aziz MA, Wright A, Laszlo A, De Muynck A, Portaels F, Van Deun A, Wells C, Nunn P, Blanc L, Raviglione M 2006. WHO/International Union against Tuberculosis and Lung Disease Global Project on Anti-tuberculosis Drug Resistance Surveillance. Epidemiology of anti-tuberculosis drug resistance (the Global Project on Anti-tuberculosis Drug Resistance Surveillance): an updated analysis. Lancet 16: 2142-54.

Banu S, Hossain A, Uddin MK, Uddin MR, Ahmed T, Khatun R, Mahmud AM, Hyder KA, Lutfor AB, Karim MS, Zaman K, Khan MA, Barua PC, Luby SP 2010. Pulmonary tuberculosis and drug resistance in Dhaka central jail, the largest prison in Bangladesh. PLOS ONE 21: e10759.

Baptista IMFD, Oelemann MC, Opromolla DVA, Suffys PN 2002. Drug resistance and genotypes of strains of Mycobacterium tuberculosis isolated from human immunodeficiency virus infected and non-infected tuberculosis patients in Bauru, São Paulo, Brazil. Mem Inst Oswaldo Cruz 97: 1147-1152.

Borsuk S, Dellagostin MM, Madeira SG, Lima C, Boffo M, Mattos I, Almeida da Silva PE, Dellagostin AO 2005. Molecular characterization of Mycobacterium tuberculosis isolates in a region of Brazil with a high incidence of tuberculosis. Microbes Infect 7: 1338-1344.

Braga JU, Werneck BA, Hijar MA 2003. Inquérito epidemiológico de resistência às drogas usadas no tratamento da tuberculose no Brasil. Bol Pneumol Sanit 11: 76-81.

Brudey K, Driscoll JR, Rigouts L, Prodinger WM, Gori A, Al-Hajoj SA, Allix C, Aristimuño L, Arora J, Baumanis V, Binder L, Cafrune PI, Cataldi A, Cheong S, Diel R, Ellermeier C, Evans JT, Fauville-Dufaux M, Ferdinand S, Garcia DE, Viedma D, Garzelli C, Gazzola L, Gomes HM, Guttierez MC, Hawkey PM, van Helden PD, Kadival GV, Kreiswirth BN, Kremer K, Kubin M, Kulkarni SP, Liens B, Lillebaek T, Ho ML, Martin C, Mokrousov I, Narvskaia O, Ngeow YF, Naumann L, Niemann S, Parwati I, Rahim Z, Rasolofo-Razanamparany V, Rasolonavalona T, Rossetti MLR, 
Rüsch-Gerdes S, Sajduda A, Samper S, Shemyakin IG, Singh UB, Somoskovi A, Skuce RA, van Soolingen D, Streicher EM, Suffys PN, Tortoli E, Tracevska T, Vincent V, Victor TC, Warren RM, Yap SF, Zaman K, Portaels F, Rastogi N, Sola C 2006. Mycobacterium tuberculosis complex genetic diversity: mining the fourth international spoligotyping database (Spoldb4) for classification, population genetics and epidemiology. BMC Microbiol 6: 23 .

Cafrune PI 2009. Avaliação da técnica de spoligotyping aplicada diretamente em amostras clínicas de pacientes com suspeita de tuberculose e caracterização epidemiológica, $\mathrm{PhD}$ Thesis, Universidade Federal do Rio Grande do Sul, Porto Alegre, 105 pp.

Cafrune PI, Possuelo LG, Ribeiro AW, Ribeiro MO, Unis G, Jarczewski CA, Rossetti MLR, Zaha A 2009. Prospective study applying spoligotyping directly to DNA from sputum samples of patients suspected of having tuberculosis. Can J Microbiol 55: 895-900.

Campos JM, Simonetti JP, Pone MV, Carvalho LA, Pereira AC, Garrido JR 1996. Disseminated bacillus Calmette-Guérin infection in HIV-infected children: case report and review. Pediatr AIDS HIV Infect 7: 429-432.

Canetti G, Fox W, Khomenko A, Mahler HT, Menon NK, Mitchison DA, Rist N, Smelev NA 1969. Advances in techniques of testing mycobacterial drug sensivity and the use of sensivity tests in tuberculosis control programmes. Bull World Health Organ 41: 21-43.

Clark PA, Cegielski JP, Hassell W 1997. TB or not TB? Increasing doorto-door response to screening. Public Health Nurs 14: 268-271.

Dalla Costa ER, Ribeiro MO, Silva MS, Arnold LS, Rostirolla DC, Cafrune PI, Espinoza RC, Palaci M, Telles MA, Ritacco V, Suffys PN, Lopes ML, Campelo CL, Miranda SS, Kremer K, da Silva PE, Fonseca LS, Ho JL, Kritski AL, Rossetti MLR 2009. Correlations of mutations in $k a t \mathrm{G}$, oxyR-ahpC and inh $\mathrm{A}$ genes and in vitro susceptibility in Mycobacterium tuberculosis clinical strains segregated by spoligotype families from tuberculosis prevalent countries in South America. BMC Microbiol 19: 39.

Dara M, Grzemska M, Kimerling ME, Reyes H, Zagorskiy A 2009. Guidelines for control of tuberculosis in prisions. Available from: pdf.usaid.gov/pdf_docs/PNADP462.pdf.

Filliol I, Motiwala AS, Cavatore M, Qi W, Hazbon MH, Bobadilla del Valle M, Fyfe J, Garcia-Garcia L, Rastogi N, Sola C, Zozio T, Guerrero MI, Leon CI, Crabtree J, Angiuoli S, Eisenach KD, Durmaz R, Joloba ML, Rendon A, Sifuentes-Osornio J, Ponce de Leon A, Cave MD, Fleischmann R, Whittam TS, Alland D 2006. Global phylogeny of Mycobacterium tuberculosis based on single nucleotide polymorphism (SNP) analysis: insights into tuberculosis evolution, phylogenetic accuracy of other DNA fingerprinting systems and recommendations for a minimal standard SNP. Set $J$ Bacteriol 188: 759-772.

Fournet N, Sanchez A, Massari V, Penna L, Natal S, Biondi E, Larouzé B 2006. Development and evaluation of tuberculosis screening scores in Brazilian prisons. Public Health 120: 976-983.

Gagneux S, de Riemer K, Van T, Kato-Maeda M, Jong BC, Narayanan S, Nicol M, Niemann S, Kremer K, Gutierrez MC, Hilty M, Hopewell PC, Small PM 2006. Variable host-pathogen compatibility in Mycobacterium tuberculosis. Proc Natl Acad Sci 103: 2869-2873.

Ignatova A, Dubiley S, Stepanshina V, Shemyakin I 2006. Predominance of multidrug-resistant LAM and Beijing family strains among Mycobacterium tuberculosis isolates recovered from prison inmates in Tula region, Russia. J Med Microbiol 55: 1413-1418.

Ijaz K, Yang Z, Templeton G, Stead WW, Bates JH, Cave MD 2004. Persistence of a strain of Mycobaterium tuberculosis in a prison system. Int J Tub Lung Dis 8: 994-1000.

Kamerbeek J, Schouls L, Kolk A, van Agterveld M, van Soolingen D, Kuijper S, Bunschoten A, Molhuizen H, Shaw R, Goyal M, van
Embden J 1997. Simultaneous detection and strain differentiation of Mycobacterium tuberculosis for diagnosis and epidemiology. J Clin Microbiol 35: 907-914.

Kudoh S, Kudoh TA 1974. A simple technique for culturing tubercle bacilli. Bull World Health Organ 51: 71-82.

Lazzarini LC, Spindola SM, Bang H, Gibson AL, Weisenberg S, da Silva Carvalho W, Augusto CJ, Huard RC, Kritski AL, Ho JL 2008. RD Rio Mycobacterium tuberculosis infection is associated with a higher frequency of cavitary pulmonary disease. $J$ Clin Microbiol 46: 2175-2183.

Lee ASG, Lim IHK, Tang LLH, Telenti A, Wong SY 1999. Contribution of kasA analysis to detection of isoniazid-resistant Mycobacterium tuberculosis in Singapore. Antimicrob Agents Chemother 43: 2087-2089.

Legrand J, Sanchez A, Le Pont F, Camacho L, Larouze B 2008. Modeling the impact of tuberculosis control strategies in highly endemic overcrowded prisons. PLoS ONE 3: 2100.

Lipin MY, Stepanshina VN, Shemyakin IG, Shinnick TM 2007. Association of specific mutations in $k a t \mathrm{G}, r p o \mathrm{~B}, r p s \mathrm{~L}$ and rrs genes with spoligotypes of multidrug-resistant Mycobacterium tuberculosis isolates in Russia. Clin Microbiol Infect 13: 620-626.

Lobacheva T, Asikainen T, Giesecke J 2007. Risk factors for developing tuberculosis in remand prisons in St. Petersburg, Russia - a case-control study. Eur J Epidemiol 22: 121-127.

Mac Neil RJ, Mc Rill C, Steinhauser G, Weisbuch JB, Williams E, Wilson ML 2005. Jails, a neglected opportunity for tuberculosis prevention. Am J Prev Med 28: 225-228.

March F, Coll P, Guerrero RA, Busquets E, Cayla JA, Prats G 2000. Predictors of tuberculosis transmission in prisons: an analysis using conventional and molecular methods. AIDS 14: 525-535.

Moreira-Oliveira MS, Oliveira HB, Pace F, Stehling EG, Rocha MMM, Aily DCG, Brocchi M, Silveira WD 2008. Molecular genotyping and epidemiology of Mycobacterium tuberculosis isolates obtained from inmates of correctional institutions of Campinas, Southeast Brazil. Braz J Infec Dis 12: 487-493.

MS/SVS - Ministério da Saúde/Secretaria de Vigilância em Saúde 2008. Manual Nacional de Vigilância Laboratorial da Tuberculose e outras Micobactérias. Departamento de Vigilância Epidemiológica. Available from: portal.saude.gov.br/portal/saude/area. cfm?id_area $=1133$.

MS/SVS - Ministério da Saúde/Secretaria de Vigilância em Saúde 2010. Manual de Recomendações para o Controle da Tuberculose. Departamento de Vigilância Epidemiológica. Available from: portal.saude.gov.br/portal/arquivos/pdf/manual_de_recomendacoes controle tb novo.pdf.

Oliveira HB, Cardoso JC 2004. Tuberculose no sistema prisional de Campinas, Säo Paulo, Brasil. Rev Panam Salud Publica 15: 194-199.

Parwati I, van Crevel R, van Soolingen D 2010. Possible underlying mechanisms for successful emergence of the Mycobacterium tuberculosis Beijing genotype strains. Lancet Infect Dis 10: 103-111.

Perizzolo PF, Dalla Costa ER, Ribeiro AW, Spies FS, Ribeiro MO, Dias CF, Unis G, Silva PA, Gomes HM, Suffys PN, Rossetti MLR 2012. Characteristics of multidrug-resistant Mycobacterium tuberculosis in southern Brazil. Tuberculosis 92: 56-59.

Rieder HL, Anderson C, Dara M, Hauer B, Helbling PK, Kam M, Zwahlen M 2011. Methodological issues in quantifying the magnitude of the tuberculosis problem in a prison population. Int $J$ Tuberc Lung Dis 15: 662-667.

Ritacco V, Iglesias MJ, Ferrazoli L, Monteserin J, Dalla Costa ER, Cebollada A, Morcillo N, Robledo J, de Waard JH, Araya P, Ari- 
stimuño L, Díaz R, Gavin P, Imperiale B, Simonsen V, Zapata EM, Jiménez MS, Rossetti MLR, Martin C, Barrera L, Samper S 2011. Conspicuous multidrug-resistant Mycobacterium tuberculosis cluster strains do not trespass country borders in Latin America and Spain. Infect Genet Evol 12: 711-717.

Sanchez AR, Massari V, Gerhardt G, Barreto AW, Cesconi V, Pires J, Espínola AB, Biondi E, Larouzé B, Camacho LAB 2007. Tuberculosis in Rio de Janeiro prisons, Brazil: an urgent public health problem. Cad Saude Publica 23: 545-552.

Sequera CM, Delgado SV, Araque MW, Torrealba OM, Núñez MR, da Mata JO, Abadía PE, Takiff H, de Waard J 2008. Mycobacterium tuberculosis: espoligotipos en el estado Carabobo, Venezuela. Rev Chil Infect 25: 362-367.

Supply P, Lesjean S, Savine E, Kremer K, van Soolingen D, Locht C 2001. Automated high-throughput genotyping for study of global epidemiology of Mycobacterium tuberculosis based on mycobacterial interspersed repetitive units. J Clin Microbiol 39: 3563-3571.
Todrys KW, Amon JJ, Malembeka G, Clayton M 2011. Imprisoned and imperiled: access to HIV and TB prevention and treatment and denial of human rights, in Zambian prisons. J Int AIDS Soc 14: 8.

Valim ARM, Rossetti ML, Ribeiro MO, Zaha A 2000. Mutations in the rpoB gene of multidrug-resistant Mycobacterium tuberculosis isolates from Brazil. J Clin Microbiol 38: 3119-3122.

van Embden JD, Cave MD, Crawford JT, Dale JW, Eisenach KD, Gicquel B, Hermans SP, Martin C, Mcadam R, Shinnick TM, Small PM 1993. Strain identification of Mycobacterium tuberculosis by DNA fingerprinting: recommendations for a standardized methodology. J Clin Microbiol 31: 406-409.

WHO - World Health Organization 1998. Guidelines for the control of tuberculosis in prisons, WHO, Geneva, $90 \mathrm{pp}$.

Zhang M, Yue J, Yang Y, Zhang H, Lei J, Jin R, Zhang X, Wang H 2005. Detection of mutations associated with isoniazid resistance in Mycobacterium tuberculosis isolates from China. J Clin Microbiol 43: 5477-5482. 